\title{
Joint replacements in the Canadian Armed Forces
}

Max Talbot, MD

Accepted Dec. 5, 2019

Correspondence to:

M. Talbot

Canadian Armed Forces

6363 Notre-Dame Est

Montréal QC H1N 3R9

DOI: 10.1503/cjs.016419

\section{SUMmaRY}

There is currently no consensus on the appropriate sports and occupational restrictions for military service members with a joint replacement. Data from the United States show that $14 \%$ of military patients complete an operational deployment after the index surgery. No published data are available on arthroplasty in the militaries of other North Atlantic Treaty Organization countries. Research is needed to determine the appropriate medical employment limitations for Canadian Armed Forces members with a knee or hip replacement. Service members wanting to continue military service should be carefully screened to ensure that their duties do not compromise the longevity of the implant and that the risk of mission-threatening complications is minimal.
$\mathbf{J}$ oint replacements are common surgical procedures for end-stage degenerative joint disease. They provide almost complete relief of symptoms and substantially improve quality of life. ${ }^{1}$ Approximately 130000 joint replacements are performed annually in Canada, most of which are total knee (TKA) and total hip arthroplasties (THA). ${ }^{2}$ Although more common in older adults, approximately $8.5 \%$ are performed in patients younger than 55 years of age. Both THA and TKA are susceptible to complications including periprosthetic fractures, dislocation and aseptic loosening. ${ }^{2}$ Many surgeons recommend against high-impact activities following the procedure to avoid complications and extend the life of the implant..$^{3-6}$ These restrictions can be particularly difficult to enforce in younger patients who demand active lifestyles. Activity recommendations are possibly becoming more liberal, perhaps because of greater surgeon confidence in modern implants. ${ }^{7,8}$ Osteoarthritis, the indication for the vast majority of joint replacements, is frequent in military members and veterans because of the rigors of military service and as a consequence of extremity war injuries. ${ }^{9,10}$ Therefore, joint replacements are relatively common in military patients. This raises difficult questions concerning the appropriate sports and occupational restrictions for service members who have undergone THA or TKA.

Several studies provide insights into joint replacements in the United States Armed Forces. Jorgensen and colleagues described a series of 183 hip replacements performed on US Army service members between 2004 and 2010. ${ }^{11}$ At a minimum of 2 years postoperatively, $31 \%$ were still on active duty, $24 \%$ had been medically separated and $45 \%$ had retired. Twenty-six patients completed an operational deployment after the surgical procedure. In this group, 4 patients reported hip pain during the deployment and another required the drainage of a subcutaneous abscess and was subsequently diagnosed with a deep infection. Belmont and colleagues reported on 159 US Army soldiers on active duty who underwent total knee replacement between 2007 and 2012. ${ }^{12}$ At an average follow-up of 4 years, $18 \%$ had been medically separated and the rest had retired or finished their duty commitment. Twenty patients completed an operational deployment, including 2 with bilateral knee 
replacements. Aside from knee pain, reported by 2 patients, there were no complications during these deployments. A separate study focused on the outcome of deployments in 45 US service members who had undergone a hip or a knee replacement by a single surgeon between 2005 and $2008 .{ }^{13}$ Sixteen patients completed an operational deployment at an average of 21 months postoperatively. No complications occurred, but the majority of patients reported limitations with sprinting and loaded marches. Discomfort while sitting in military vehicles or aircraft was also frequent. Finally, Daniele and colleagues performed the most comprehensive analysis of joint replacements in US service members. ${ }^{14}$ From 2004 to 2014, 3805 military patients underwent at least 1 joint replacement procedure. The overall incidence of joint replacement was 2.43 per 10000 persons-years. Hip and knee arthroplasty were the most frequent procedures, with an incidence of 1.08 and 1.16 per 10000 person-years, respectively. The incidence of arthroplasty increased significantly during the study period. As expected, service members older than 45 years of age were disproportionately affected, with an incidence reaching 26.3 per 10000 person-years in this group. Two years after surgery, $51 \%$ of patients with a hip arthroplasty and $42 \%$ of patients with a knee arthroplasty were still serving. Fourteen percent of all patients were deployed with the prosthetic joint. These reports show that a substantial percentage of patients are able to continue their military duties and a complete operational deployment after a hip or knee replacement.

Differences in occupational, medical and fitness standards make it challenging to extrapolate these results to militaries in other North Atlantic Treaty Organization (NATO) countries. In the Canadian Armed Forces (CAF), the Universality of Service principle requires that all members be capable of safely performing 6 general military tasks: an escape to cover, the extrication of a casualty from a vehicle, picking and digging, the construction of a sandbag fortification, carrying a stretcher, and carrying pickets and wire. ${ }^{15,16}$ For most CAF members, the FORCE test is used annually as a surrogate for these tasks. ${ }^{17}$ The test includes $20 \mathrm{~m}$ sprints, a sandbag drag, loaded shuttles and dynamic sandbag lifts. ${ }^{18}$ In addition to annual fitness testing, many military members perform strenuous physical work under austere conditions. Therefore, a risk analysis is required to determine if individuals can reasonably continue military service after a joint replacement. An estimate of the baseline risk for CAF members, who can serve until age 60 , is provided by the revision rates for patients younger than 55 published by national joint replacement registries. In this age category, the Canadian Joint Replacement Registry reports a cumulative 5-year THA revision rate of $2.4 \%$ in men and $3.1 \%$ in women. ${ }^{2}$ For TKA, the 5 -year revision rates are $6.5 \%$ for men and $5 \%$ for women. ${ }^{2}$ The United Kingdom's National Joint Registry estimates 10 -year revision rates of less than $9 \%$ for hip replacements and less than $11 \%$ for knee replacements in patients younger than 55 years of age. ${ }^{19}$ The Australian National Joint Replacement Registry reports 10-year revision rates of $5.9 \%$ for THA and $10.5 \%$ for TKA. ${ }^{20}$ In addition, there is a small risk of complications that do not require revision, such as hip dislocations treated with a closed reduction and fractures treated with internal fixation. ${ }^{21-23}$ The additional risk that CAF members would incur from annual fitness testing, deployments and general duties is difficult to estimate.

The CAF and NATO use risk matrices to assess the fitness of military members for expeditions based on the probability of exacerbations (complications), their consequences for the patient and the resulting risk to the mission. $^{24,25}$ This methodology should be applied to TKA and THA by a panel of civilian arthroplasty experts and military orthopedic surgeons. In addition, a multidisciplinary research effort is needed to address key knowledge gaps, including the epidemiology of joint replacements in the $\mathrm{CAF}$, the occupational outcome of retained service members, the risks of physical fitness testing and the long-term outcome of joint replacements in veterans. Joint replacements in military members are becoming increasingly common; subject matter experts must be actively involved to generate evidence-based policy recommendations. In the interim, selected CAF members may be able to serve with a joint replacement if they have a low risk of missionthreatening complications and if their duties do not unduly compromise the long-term survival of the implant.

Affiliations: Department of Surgery, Division of Orthopaedic Surgery, McGill University, Montreal, Que. and Chief of Orthopaedic Surgery, Canadian Armed Forces.

Competing interests: None declared.

Disclaimer: This article reflects the personal views of the author. It does not represent the official policy of the Department of National Defence, the Canadian Armed Forces, or the Royal Canadian Medical Service.

\section{References}

1. Konopka JF, Lee YY, Su EP, et al. Quality-adjusted life years after hip and knee arthroplasty: health-related quality of life after 12,782 joint replacements. FBFS Open Access 2018;3:e007.

2. Canadian Institute for Health Information. Hip and Knee Replacements in Canada, 2017-2018: Canadian Foint Replacement Registry Annual Report. Ottawa (ON): CIHI; 2019.

3. Klein GR, Levine BR, Hozack WJ, et al. Return to athletic activity after total hip arthroplasty. Consensus guidelines based on a survey of the Hip Society and American Association of Hip and Knee Surgeons. 7 Arthroplasty 2007;22:171-5.

4. Bradley BM, Moul SJ, Doyle FJ, et al. Return to sporting activity after total hip arthroplasty - a survey of members of the British Hip Society. F Arthroplasty 2017;32:898-902.

5. Swanson EA, Schmalzried TP, Dorey FJ. Activity recommendations after total hip and knee arthroplasty: a survey of the American Association for Hip and Knee Surgeons. 7 Arthroplasty 2009;24(Suppl): 120-6.

6. Laursen MK, Andersen JB, Andersen MM, et al. Danish surgeons allow the most athletic activities after total hip and knee replacement. Eur 7 Orthop Surg Traumatol 2014;24:1571-7. 
7. Golant A, Christoforou DC, Slover JD, et al. Athletic participation after hip and knee arthroplasty. Bull NYU Hosp ft Dis 2010;68:76-83.

8. Jassim SS, Douglas SL, Haddad FS. Athletic activity after lower limb arthroplasty: a systematic review of current evidence. Bone foint 7 2014;96-B:923-7.

9. Cameron KL, Hsiao MS, Owens BD, et al. Incidence of physiciandiagnosed osteoarthritis among active duty United States military service members. Arthritis Rheum 2011;63:2974-82.

10. Rivera JC, Wenke JC, Buckwalter JA, et al. Posttraumatic osteoarthritis caused by battlefield injuries: the primary source of disability in warriors. 7 Am Acad Orthop Surg 2012;20(Suppl 1):S64-9.

11. Jorgensen AY, Waterman BR, Hsiao MS, et al. Functional outcomes of hip arthroplasty in active duty military service members. 7 Surg Orthop Adv 2013;22:16-22.

12. Belmont PJ Jr, Heida K, Keeney JA, et al. Return to work and functional outcomes following primary total knee arthroplasty in U.S. military service members. 7 Arthroplasty 2015;30:968-72.

13. Glebus GP, Feather TW, Hsu JR, et al. Return to duty and deployment after major joint arthroplasty. 7 Arthroplasty 2013;28:1270-3.

14. Daniele DO, Taubman SB, Clark LL. Incidence of joint replacement among active component service members, U.S. Armed Forces, 2004-2014. MSMR 2015;22:2-8.

15. Government of Canada. Defense Administrative Orders and Directives: 5023-1, Minimum Operational Standards Related to Universality of Service. Ottawa (ON): GOC; 2018. Available: https://www. canada.ca/en/department-national-defence/corporate/policies -standards/defence-administrative-orders-directives/5000 -series/5023/5023-1-minimum-operational-standards-related -to-universality-of-service.html (accessed 2019 July 30).

16. Canadian Forces Morale and Welfare Service. Common Military Task Fitness Evaluation. Ottawa (ON): CAF; 2019. Available: https://www. cafconnection.ca/National/Programs-Services/For-Military-Personnel/ Military-Fitness/FORCE-Program/Common-Military-Task-Fitness -Evaluation.aspx (accessed 2019 Aug. 15).
17. Gagnon P, Spivock M, Reilly T, et al. The FORCE fitness profile adding a measure of health-related fitness to the Canadian Armed Forces operational fitness evaluation. 7 Strength Cond Res 2015; 29(Suppl 11):S192-8.

18. Canadian Forces Morale and Welfare Service. FORCE Evaluation. Ottawa (ON): CAF; 2019. Available: https://www.cafconnection.ca/ National/Programs-Services/For-Military-Personnel/Military-Fitness /FORCE-Program/FORCE-Evaluation.aspx (accessed 2019 Aug. $15)$.

19. National Joint Registry for England, Wales, Northern Ireland and the Isle of Man. National foint Registry 16th Annual Report. Available: https://reports.njrcentre.org.uk/Portals/0/PDFdownloads/NJR\%20 16th\%20Annual\%20Report\%202019.pdf (accessed 2019 Oct. 31).

20. Australian Orthopaedic Association. National foint Replacement Registry Annual Report 2019. Available: https://aoanjrr.sahmri.com/ documents/10180/668596/Hip\%2C+Knee+\%26+Shoulder+Arthro plasty/c287d2a3-22df-a3bb-37a2-91e6c00bfcf0 (accessed 2019 Oct. 31).

21. Mei XY, Gong YJ, Safir O, et al. Long-term outcomes of total hip arthroplasty in patients younger than 55 years: a systematic review of the contemporary literature. Can 7 Surg 2019;62:249-58.

22. Meek RM, Norwood T, Smith R, et al. The risk of peri-prosthetic fracture after primary and revision total hip and knee replacement. $\mathcal{F}$ Bone foint Surg Br 2011;93:96-101.

23. Devane PA, Wraighte PJ, Ong DC, et al. Do joint registries report true rates of hip dislocation? Clin Orthop Relat Res 2012;470:3003-6.

24. Russell R, Reid A, Borgers G, et al. A NATO guide for assessing deployability for military personnel with chronic medical conditions: medical fitness for expeditionary missions, Task Group 174, Human Factors, and Medicine Panel. Mil Med 2014;179:1404-11.

25. Government of Canada. Medical Risk Matrix. Ottawa (ON): GOC;; 2018. Available: https://www.canada.ca/en/department-national -defence/corporate/policies-standards/medical-standards-military -occupations/medical-risk-matrix.html (accessed 2019 Sept. 15). 